\title{
Effect of catheter ablation versus antiarrhythmic drugs on atrial fibrillation: A meta-analysis of randomized controlled trials
}

\author{
LEI-ZHI SHI ${ }^{1}$, RUI HENG ${ }^{1}$, SHI-MIN LIU ${ }^{2}$ and FEI-YAN LENG ${ }^{1}$ \\ Departments of ${ }^{1}$ Thoracic Surgery and ${ }^{2}$ Internal Medicine, Linyi People's Hospital, Linyi, Shandong 276000, P.R. China
}

Received September 15, 2014; Accepted May 18, 2015

DOI: $10.3892 /$ etm.2015.2545

\begin{abstract}
The aim of the present study was to compare the health outcomes of catheter ablation therapy against those of antiarrhythmic drugs (AADs) in the management of atrial fibrillation (AF). The effects of catheter ablation and AADs on a number of parameters were compared, including AF recurrence, all-cause mortality, stroke/transient ischemic attack (TIA) and quality of life (QoL). A systematic literature search of PubMed, Embase and the Cochrane Central Register of Controlled Trials was conducted to obtain relevant randomized controlled trials. The relative risks (RRs) and 95\% confidence intervals (CIs) of AF recurrence, all-cause mortality and stroke/TIA between catheter ablation and AADs were subsequently calculated. Weighted mean differences (WMDs) and $95 \%$ CIs were used to evaluate the QoL between the two therapy groups. In total, 11 randomized trials, which included 1,763 AF patients, were eligible for the meta-analysis. Overall, the results indicated that catheter ablation produces superior outcomes compared with AADs in reducing AF recurrence (RR, 0.47; 95\% CI, 0.38-0.58; $\mathrm{P}<0.001$ ) and improving the QoL (physical component summary: WMD, 2.23; 95\% CI, 0.24-4.21; $\mathrm{P}=0.03$; mental component summary: WMD, 2.69; 95\% CI, 0.04-5.35; $\mathrm{P}=0.05)$. However, no statistically significant difference was identified between the two groups with regard to the incidence of all-cause mortality (RR, 0.87; 95\% CI, 0.37-2.06; $\mathrm{P}=0.76)$ and stroke/TIA (RR, 1.83; 95\% CI, $0.73-4.55 ; \mathrm{P}=0.20)$. In summary, catheter ablation was demonstrated to markedly reduce AF recurrence and improve QoL when compared with AAD therapy. However, the incidence rates of all-cause mortality and stroke/TIA were comparable between catheter ablation and AAD therapy.
\end{abstract}

Correspondence to: Dr Fei-Yan Leng, Department of Thoracic Surgery, Linyi People's Hospital, 27 Jiefang Road, Linyi, Shandong 276000, P.R. China

E-mail: feiyanleng@163.com

Key words: catheter ablation, antiarrhythmic drugs, atrial fibrillation, meta-analysis

\section{Introduction}

Atrial fibrillation (AF) is the most prevalent form of arrhythmia observed in clinical practice, with a high population prevalence in industrial and developing countries (1-3). Furthermore, the prevalence of AF is increasing markedly in elderly populations (4). AF is associated with a three-fold risk of heart failure and a five-fold risk of stroke $(5,6)$. In addition to the significant rate of morbidity, $\mathrm{AF}$ is associated with a 1.5-1.9-fold risk of mortality (7). Therefore, AF has become a substantial health burden for patients and societies worldwide.

According to the present guidelines for the management of $\mathrm{AF}$, antiarrhythmic drugs (AADs) are the primary strategy for treating $\mathrm{AF}(5,6)$. However, the application of AADs has encountered challenges due to their limited efficacy and potential adverse effects. Thus, catheter ablation therapy has become a generally adopted alternative technique for the treatment of AF, particularly in cases of paroxysmal or/and persistent AF. However, the management recommendations and guidelines have not yet reached a consensus with regard to the use of catheter ablation for the treatment of $\mathrm{AF}$, primarily due to the differences in ablation strategy and technique employed in different centers, in addition to relevant complications $(5,6,8)$. In previous years, a number of small to moderately sized randomized controlled trials (RCTs) have been published that directly compare the efficacy of catheter ablation and AADs for the treatment of AF (9-19). However, the number of patients enrolled in each study was limited. Therefore, a meta-analysis was conducted in the present study to comprehensively evaluate whether catheter ablation is superior to AADs for the treatment of AF. In addition, the quality of the results published by the previous studies was evaluated, as recommended by the Cochrane Collaboration.

\section{Materials and methods}

Search strategy and inclusion criteria. MEDLINE, Embase and the Cochrane Central Register of Controlled Trials databases were searched for RCTs that compared catheter ablation with AADs for the treatment of AF, without language restrictions (last search update, May 1, 2014). In addition, reference lists from initially identified articles were retrieved in order to avoid the exclusion of any relevant studies. The following medical subject heading terms were used: 'Atrial fibrillation', 'catheter ablation' and 'randomized controlled trials'. 
Studies were included if they satisfied the following criteria: i) Study design was a RCT; ii) study population consisted of human participants with paroxysmal, persistent or long-standing persistent AF; iii) interventions included pulmonary vein isolation, no matter which technique was used; and iv) follow-up was $\geq 12$ months.

Quality assessment. The methodological quality of each eligible study (risk of bias) was evaluated as recommended in the Cochrane Handbook for Systematic Reviews of Interventions (version 5.1.0) (20). The risk of bias for each trial was assessed on the basis of the prime endpoint of recurrence of AF. The following criteria were evaluated and assigned a value of 'high', 'low' or 'unclear' by two authors. With regard to selection bias, the authors aimed to determine whether the method of randomization was adequate and whether the treatment allocation was concealed. In addition, performance and detection biases were assessed by determining whether the participants and personnel were blinded to the intervention, and whether the outcome assessor was blinded to the intervention. With regard to attrition bias, the authors determined whether any incomplete outcome data were sufficiently assessed and handled, while reporting bias was assessed by determining whether selective outcome reporting had been identified. Finally, the existence of any additional sources of bias was analyzed.

Data extraction. Two authors independently extracted relevant data from the included trials, and disagreements were resolved by discussion and consensus. The following data were extracted from each RCT: Name of the first author, year of publication, number of patients (intervention vs. control), age of populations, composition of gender, time of follow-up, definition of primary outcome and other important clinical information. In the case of a trial being reported in multiple publications, the most complete study or the article with the longest follow-up time was selected. The primary endpoint was the recurrence of AF. Secondary endpoints included all-cause mortality, stroke/transient ischemic attack (TIA) and quality of life (QoL).

Statistical analysis. Data analysis was performed based on an intention-to-treat analysis. Relative risks (RRs) with 95\% confidence intervals (CIs) were selected to compare the differences for dichotomous outcomes, while weighted mean differences (WMDs) with $95 \%$ CIs were used to compare continuous outcomes. Heterogeneity among studies was analyzed using a $\chi^{2}$-based $\mathrm{Q}$ test and $\mathrm{I}^{2}$ statistic. If significant heterogeneity was identified $\left(\mathrm{P}<0.05\right.$ and $\left.\mathrm{I}^{2}>50 \%\right)$, a random-effects model was selected, whilst a fixed-effects model was selected in all other cases.

Begg's funnel plot and Egger's test were used to evaluate the significance of the publication bias. The meta-analysis was performed using Stata software, version 11.0 (StataCorp, College Station, TX, USA) and Revman 5.1 software (The Cochrane Collaboration). A two-tailed P-value of $<0.05$ was considered to indicate a statistically significant difference. Finally, the quality of the evidence was evaluated using the Grades of Recommendation, Assessment, Development and Evaluation (GRADE) system (21).

\section{Results}

Literature search and selection. A flow diagram of the literature search is presented in Fig. 1. Briefly, 1,917 potentially relevant articles were identified following electronic and additional manual searches. Among the 1,917 publications yielded, 900 articles were excluded following screening of the titles and abstracts. Subsequently, 26 full-text articles were assessed for eligibility. Among these, 15 articles were further excluded for a variety of reasons, as described in Fig. 1. Finally, 11 RCTs involving 1,763 patients with AF were included in the meta-analysis (9-19).

Study characteristics and risk of bias assessment. Primary characteristics of the 11 RCTs included in the meta-analysis are shown in Table I. The 11 trials were published between 2003 and 2013. Among them, four trials enrolled only patients with paroxysmal AF $(13,15,16,18)$, two trials enrolled patients with only persistent AF $(11,19)$, and the remaining five trials enrolled patients with paroxysmal and persistent AF $(9,10,12,14,17)$. Three trials enrolled patients to receive pulmonary vein ablation as the first-line therapy $(10,17,18)$, whereas the remaining studies included patients that had failed at least one AAD treatment protocol or were intolerant of AADs. The majority of the trials compared catheter ablation with AADs, with the exception of one trial that compared catheter ablation plus AADs with single AAD administration (12). All the AF patients assigned to catheter ablation underwent a single ablation procedure in four of the studies $(9,10,12,14)$. In the other trials, patients that received catheter ablation therapy underwent two or more ablation procedures in the blanking period when required.

A risk of bias assessment was performed for each trial, and the results are presented in Fig. 2A. Of the 11 trials, six trials adopted appropriate methods to generate the random sequence $(10-12,14,15,18)$. One study reported allocation concealment using sealed envelopes (15); however, the methods of concealment in other trials were not mentioned. Blinding of the outcome assessors was reported in three trials $(11,12,18)$. The overall risk of bias is presented in Fig. 2B.

Analysis of the primary outcome, recurrence of $A F$. The majority of the included trials considered the recurrence of $\mathrm{AF}$ and/or atrial tachyarrhythmia as their primary end point. Therefore, the overall effect of catheter ablation against AADs for the recurrence of AF was assessed. The results indicated that catheter ablation was able to significantly reduce the recurrence of $\mathrm{AF}$, as compared with AADs (RR, 0.47; 95\% CI, 0.38-0.58; $\mathrm{P}<0.001$; Fig. 3). Significant heterogeneity was detected among the trials $\left(\mathrm{Q}=26.31 ; \mathrm{I}^{2}=62 \% ; \mathrm{P}=0.003\right)$.

Three trials enrolled drug-naive patients and the result was similar to the overall effect (RR, 0.50; 95\% CI, 0.27-0.92; $\mathrm{P}=0.03)$. Sensitivity analysis indicated that no single study significantly altered the combined effect, which ranged between 0.45 (95\% CI, 0.37-0.55) and 0.41 (95\% CI, 0.43-0.62).

Analysis of the secondary outcomes, all-cause mortality, stroke and/or TIA, and QoL. A total of 18 mortalities were reported in six studies, among which eight cases had received catheter ablation and 10 cases had received AADs. No 


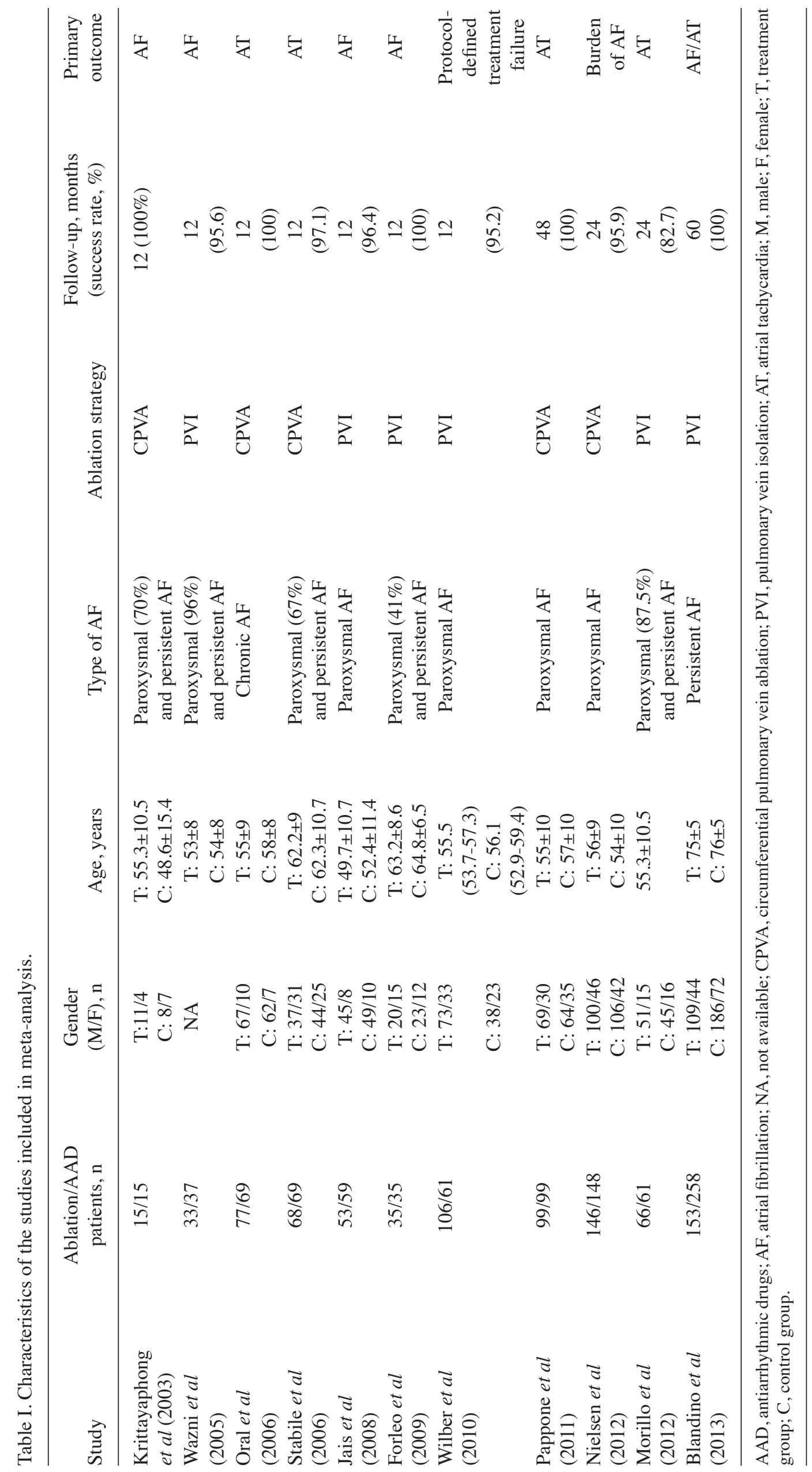




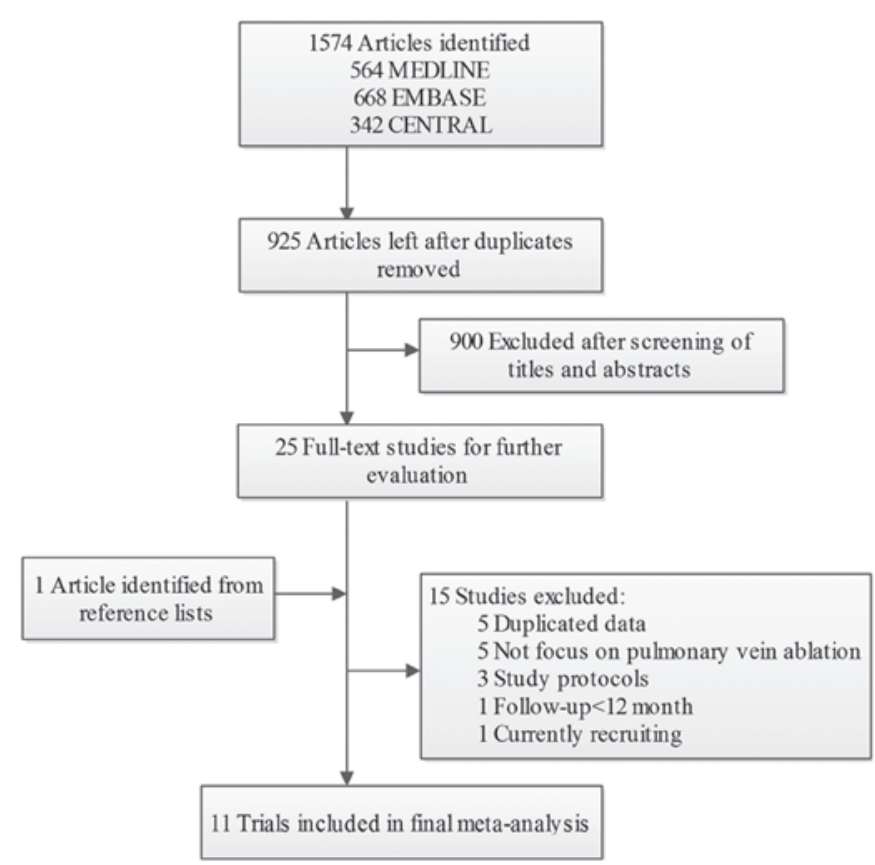

Figure 1. Flow diagram of the included studies in the meta-analysis.

statistically significant difference in the mortality rate was detected between the catheter ablation and AAD treatment groups (RR, 0.87; 95\% CI, 0.37-2.06; P=0.76; Fig. 4), with no evidence for significant heterogeneity $\left(\mathrm{Q}=2.12, \mathrm{I}^{2}=0 \%\right.$, $\mathrm{P}=0.83$ ).

A total of 17 strokes/TIA were reported, among which 10 events occurred in catheter ablation patients and seven events occurred in AAD patients. However, no statistically significant difference was detected between the catheter ablation and AAD therapies (RR, 1.83; 95\% CI, 0.73-4.55; $\mathrm{P}=0.20$; Fig. 5), and there was no evident heterogeneity $(\mathrm{Q}=0.39$; $\left.\mathrm{I}^{2}=0 \% ; \mathrm{P}=0.98\right)$.

Four studies included results with regard to the differences in the QoL outcome, including the physical component summary (PCS) and the mental component summary (MCS). When compared with the baseline observations, the catheter ablation and AAD treatment groups exhibited a significantly improved QoL at the end of the study. However, catheter ablation was shown to result in improved QoL outcomes compared with AADs (PCS: WMD, 2.23; 95\% CI, 0.24-4.21; $\mathrm{P}=0.03$; MCS: WMD, 2.69; 95\% CI, 0.04-5.35; P=0.05; Fig. 6).

Quality assessment and publications bias. The quality of the evidence was evaluated using the GRADE system. As shown in Table II, the evidence quality of the outcomes ranged between low and high. Potential publication bias was assessed using Begg's funnel plot and Egger's test, and the results indicated that there was no potential publication bias (Fig. 7; Egger's test, $\mathrm{P}=0.066)$.

\section{Discussion}

The primary finding of the present meta-analysis was that the recurrence of AF was notably reduced in patients that received catheter ablation therapy, as compared with those that received AADs. Furthermore, catheter ablation treatment was shown

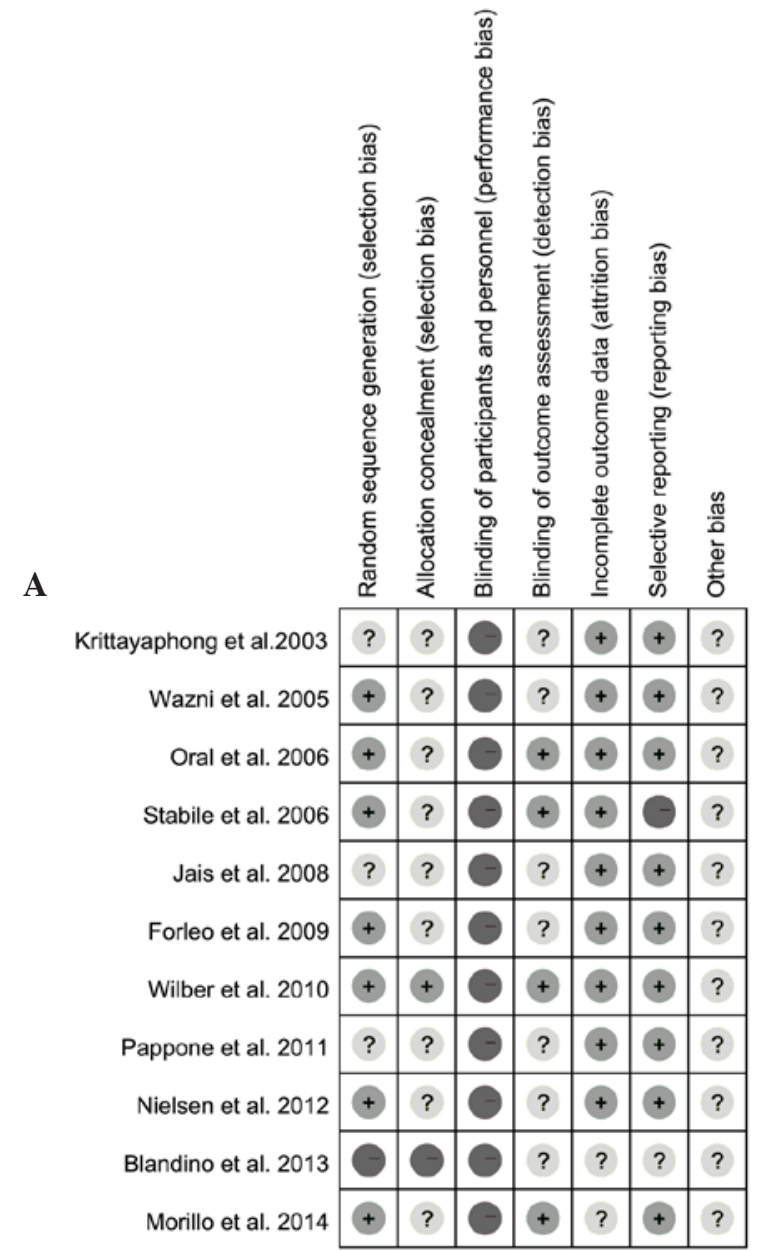

B

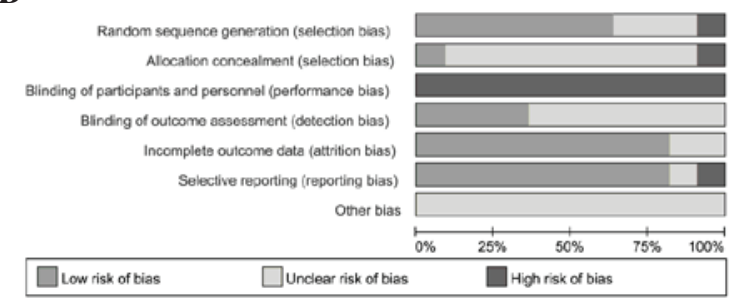

Figure 2. Risk of bias assessment for the included trials. (A) Summary of the risk of bias for each individual trial. (B) Overall risk of bias.

to result in an improved QoL when compared with AADs. However, no statistically significant difference was identified between two groups with regard to the incidence of all-cause mortality and stroke/TIA.

In the present study, a significant reduction in recurrent AF was observed in the patients who underwent catheter ablation therapy, as compared with the patients that received AADs. Restoration of a sinus rhythm is considered to improve the long-term survival rates and reduce the incidence of stroke/TIA in general AF patients $(22,23)$. In addition, a previous observational study indicated that catheter ablation is superior to AADs in reducing the all-cause mortality rate (24). However, in the present meta-analysis, no statistically significant difference was detected between the catheter ablation and AAD therapy with regard to the rates of mortality and stroke/TIA, for which there are a number of possible explanations. Firstly, the current study design was different to that of the 


\begin{tabular}{|c|c|c|c|c|c|c|c|c|}
\hline \multirow[b]{2}{*}{ Study } & \multicolumn{2}{|c|}{ Catheter ablation } & \multicolumn{2}{|c|}{ AADs } & \multirow{2}{*}{\multicolumn{2}{|c|}{$\begin{array}{c}\text { Risk Ratio } \\
\mathrm{M}-\mathrm{H}, \text { Random, } 95 \% \mathrm{Cl}\end{array}$}} & \multirow{2}{*}{\multicolumn{2}{|c|}{$\begin{array}{c}\text { Risk Ratio } \\
\text { M-H, Random. } 95 \% \mathrm{Cl}\end{array}$}} \\
\hline & Events & Total & Events & Total & & & & \\
\hline Krittayaphong et al.2003 & 3 & 15 & 9 & 15 & $3.1 \%$ & $0.33[0.11,0.99]$ & & \\
\hline Wazni et al. 2005 & 4 & 33 & 22 & 37 & $3.9 \%$ & $0.20[0.08,0.53]$ & & \\
\hline Stabile et al. 2006 & 30 & 68 & 63 & 69 & $13.2 \%$ & $0.48[0.37,0.64]$ & & \\
\hline Oral et al. 2006 & 20 & 77 & 29 & 69 & $9.3 \%$ & $0.62[0.39,0.99]$ & & \\
\hline Jais et al. 2008 & 7 & 53 & 42 & 59 & $5.9 \%$ & $0.19[0.09,0.38]$ & & \\
\hline Forleo et al. 2009 & 7 & 35 & 20 & 35 & $5.8 \%$ & $0.35[0.17,0.72]$ & & \\
\hline Wilber et al. 2010 & 35 & 106 & 47 & 61 & $12.6 \%$ & $0.43[0.32,0.58]$ & & \\
\hline Pappone et al. 2011 & 27 & 99 & 43 & 99 & $10.8 \%$ & $0.63[0.42,0.93]$ & & \\
\hline Nielsen et al. 2012 & 22 & 146 & 43 & 148 & $9.5 \%$ & $0.52[0.33,0.82]$ & & \\
\hline Blandino et al. 2013 & 37 & 153 & 141 & 259 & $12.6 \%$ & $0.44[0.33,0.60]$ & & \\
\hline Morillo et al. 2014 & 36 & 66 & 44 & 61 & $13.3 \%$ & $0.76[0.58,0.99]$ & & \\
\hline Total $(95 \% \mathrm{Cl})$ & & 851 & & 912 & $100.0 \%$ & $0.47[0.38,0.58]$ & & \\
\hline Total events & 228 & & 503 & & & & & \\
\hline $\begin{array}{l}\text { Heterogeneity: } \operatorname{Tau}^{2}=0.0 \\
\text { Test for overall effect: } Z=\end{array}$ & $\begin{array}{l}\mathrm{Chi}^{2}=26.31 \\
.93(\mathrm{P}<0.0 \mathrm{C}\end{array}$ & If $=10(P$ & $=0.003$ & ); $1^{2}=6$ & & & $\begin{array}{ll}0.05 & 0.2 \\
\text { Favors catheter ablation }\end{array}$ & ${ }_{n}^{1} \quad 5 \quad 20$ \\
\hline
\end{tabular}

Figure 3. Forest plot of the effects of catheter ablation vs. AADs on the recurrence of atrial fibrillation. AAD, antiarrhythmic drug; CI, confidence interval.

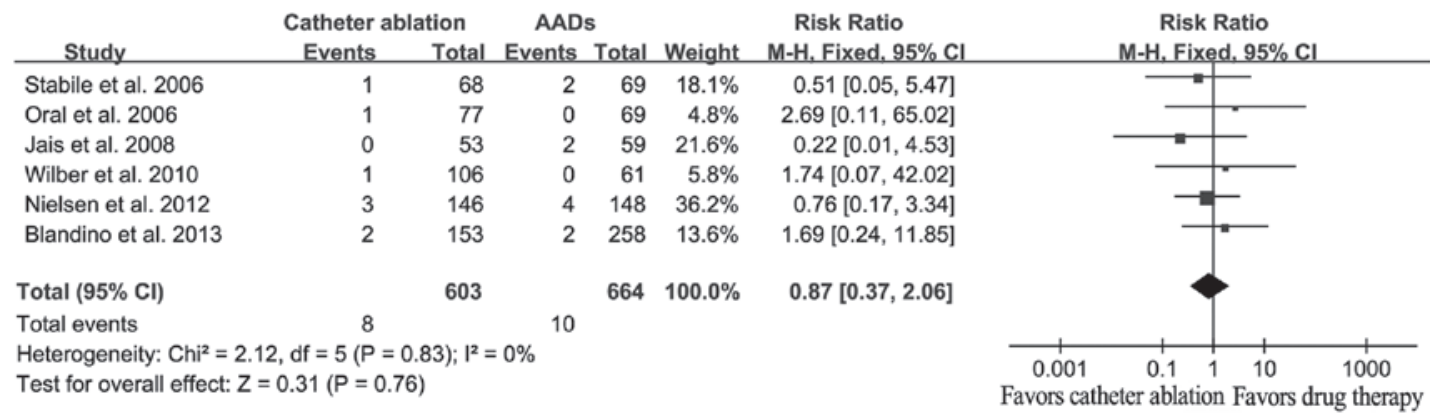

Figure 4. Forest plot of the effects of catheter ablation vs. AADs on all-cause mortality. AAD, antiarrhythmic drugs; CI, confidence interval.

\begin{tabular}{|c|c|c|c|c|c|c|c|c|}
\hline \multirow[b]{2}{*}{ Study } & \multicolumn{2}{|c|}{ Catheter ablation } & \multicolumn{2}{|c|}{ AADs } & \multirow{2}{*}{\multicolumn{2}{|c|}{$\begin{array}{cc} & \text { Risk Ratio } \\
\text { Weight } & \text { M-H. Fixed, } 95 \% \mathrm{Cl}\end{array}$}} & \multirow{2}{*}{$\begin{array}{c}\text { Risk Ratio } \\
\text { M-H, Fixed, 95\% C। }\end{array}$} & \\
\hline & Events & Total & Events & Total & & & & \\
\hline Krittayaphong et al. 2003 & 1 & 15 & 0 & 15 & $7.4 \%$ & $3.00[0.13,68.26]$ & & \\
\hline Stabile et al. 2006 & 1 & 68 & 1 & 69 & $14.8 \%$ & $1.01[0.06,15.90]$ & & \\
\hline Pappone et al. 2011 & 1 & 99 & 0 & 99 & $7.4 \%$ & $3.00[0.12,72.76]$ & & \\
\hline Nielsen et al. 2012 & 2 & 146 & 1 & 148 & $14.8 \%$ & $2.03[0.19,22.12]$ & & \\
\hline Blandino et al. 2013 & 5 & 153 & 5 & 256 & $55.6 \%$ & $1.67[0.49,5.69]$ & & \\
\hline Total $(95 \%$ Cl) & & 481 & & 587 & $100.0 \%$ & $1.83[0.73,4.55]$ & 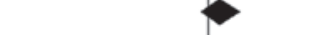 & \\
\hline Total events & 10 & & 7 & & & & & \\
\hline $\begin{array}{l}\text { Heterogeneity: } \mathrm{Ch}^{2}=0.39 \text {, } \\
\text { Test for overall effect: } Z=1\end{array}$ & $\begin{array}{l}\text { If }=4(P=0 \\
29(P=0.20\end{array}$ & $; 1^{2}=0 \%$ & & & & & $\begin{array}{cccc}0.001 & 0.1 & 1 & 10 \\
\text { Favors catheter ablation Favors dr }\end{array}$ & th \\
\hline
\end{tabular}

Figure 5. Forest plot of the effects of catheter ablation vs. AADs on stroke/transient ischemic attack. AAD, antiarrhythmic drug; CI, confidence interval.

A

\begin{tabular}{|c|c|c|c|c|c|c|c|c|}
\hline \multirow[b]{2}{*}{ Study } & \multicolumn{3}{|c|}{ Catheter ablation } & \multirow{2}{*}{\multicolumn{2}{|c|}{ AADs }} & \multirow{2}{*}{\multicolumn{2}{|c|}{ Mean Difference }} & \multirow{2}{*}{$\begin{array}{l}\text { Mean Difference } \\
\text { JV.Random. } 95 \% \text { CI }\end{array}$} \\
\hline & Mean & SD & Total & & & & & \\
\hline Jais et al. 2008 & 52 & 7.6 & 53 & 48.9 & 72.2 & $\begin{array}{ll}55 & 23.5 \%\end{array}$ & $3.10[0.31 .5 .89]$ & $1-$ \\
\hline Wilber et al. 2010 & 52 & 7.8 & 97 & 47.1 & 10.6 & $19.4 \%$ & $4.90[1.52,8.28]$ & \\
\hline Pappone et al. 2011 & 52.3 & 9 & 99 & 52.6 & 8 & $27.1 \%$ & $-0.30[-2.67,2.07]$ & - \\
\hline Nielsen et al. 2012 & 50 & 8.8 & 140 & 47.9 & 8.9 & $30.0 \%$ & $2.10[0.05,4.15]$ & $E-$ \\
\hline Total $(95 \% \mathrm{Cl})$ & & & 389 & & & $348 \quad 100.0 \%$ & $2.23[0.24,4.21]$ & \\
\hline
\end{tabular}

Test for overall effect: $Z=2.20(P=0.03)$

Favors catheter ablation Favors drug therapy

B

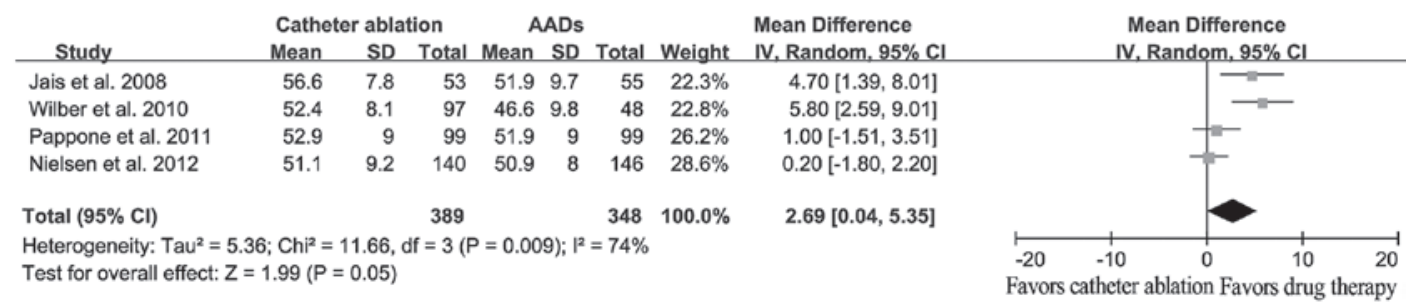

Figure 6. Forest plot of the effects of catheter ablation vs. AADs on the quality of life. (A) Physical component summary and (B) mental component summary. AAD, antiarrhythmic drug; SD, standard deviation; IV, independent variable; CI, confidence interval. 


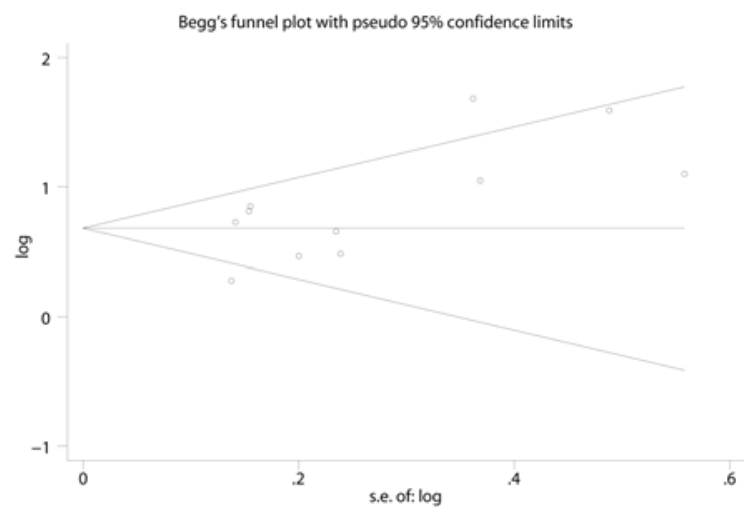

Figure 7. Begg's funnel plot for assessment of potential publication bias.

aforementioned observational study, with only RCTs included in the current meta-analysis. RCTs are considered to provide the most robust evidence for clinical practice; however, the number of participants enrolled may be insufficient to obtain statistical differences. Secondly, the duration of the follow-up period in the majority of the trials was only 12 months, which may be too short to detect a representative quantity of adverse events, particularly considering that patients in RCTs are typically younger and exhibit a low prevalence of structural heart disease. These factors limited the value of the studies for the evaluation of the long-term efficacy of catheter ablation. However, the ongoing multicenter, randomized Catheter Ablation versus Antiarrhythmic Drug Therapy for Atrial Fibrillation (CABANA) trial (no. NCT00911508), which plans to enroll $>3,000$ patients, may resolve this problem.

QoL is a key factor to consider when selecting a method of AF management. Theoretically, early catheter ablation is able to avoid the requirement for long-term drug employment and the subsequent side effects. The present study indicated that patients who underwent catheter ablation therapy had an improved QoL compared with patients that received AADs. However, the assessment of QoL is subjective, and as catheter ablation is distinct from drug therapy, blinding of the assessment is impossible. Furthermore, according to the GRADE system, the quality of evidence of QoL as a parameter is assessed as 'low'. Therefore, further studies may be required to elucidate this issue.

Cost-effectiveness is an additional key factor to take into consideration when comparing treatments for AF. However, was the ablation technique and duration differed between study centers, it is difficult to precisely evaluate the cost-effectiveness of catheter ablation compared with AADs for AF therapy. The limited information available did not permit a consensus on the cost-effectiveness of catheter ablation for AF (25-28). Thus, the cost comparison of catheter ablation and AADs requires further investigation in future RCTs.

Prior to the present study, a number of previous meta-analyses were published that compared catheter ablation with AADs for the treatment of AF (29-31). However, the present study possesses a number of advantages compared with the previous studies. Firstly, the present meta-analysis included more recently published trials, and the number of AF patients included in this meta-analysis was twice the number reported in previous studies. Furthermore, the present study 
analyzed a number of outcome markers, in addition to the primary endpoint (recurrent AF), including all-cause mortality, stroke/TIA and the change of QoL. In addition, in the present study, the quality of evidence was assessed using the GRADE system, as proposed by the Cochrane Collaboration.

However, the current meta-analysis contains a number of limitations, and the present results require cautious interpretation. Firstly, the trials included in the meta-analysis used different ablation techniques and different methods to monitor the recurrence of AF. These variations are consistent with the current status in clinical practice. Secondly, unlike real clinical practice, AF patients included in the present analysis were relatively young, with no serious structural heart diseases, and only one study (11) enrolled elderly patients ( $\geq 70$ years). Thus, when appraising the results of the present study in the real clinical practice setting, the aforementioned limitations should be considered.

In conclusion, the results of the present study demonstrated that catheter ablation therapy is superior to AADs in reducing the recurrence of AF and improving the QoL. However, there is insufficient evidence to suggest that catheter ablation is superior to AADs in reducing the long-term severe adverse events, including all-cause mortality and stroke/TIA. This issue may be clarified by the future CABANA trial (no. NCT00911508).

\section{References}

1. Naccarelli GV, Varker H, Lin J and Schulman KL: Increasing prevalence of atrial fibrillation and flutter in the United States. Am J Cardiol 104: 1534-1539, 2009.

2. Wilke T, Groth A, Mueller S, et al: Incidence and prevalence of atrial fibrillation: An analysis based on 8.3 million patients. Europace 15: 486-493, 2013.

3. Zhou ZQ and Hu DY: An epidemiological study on the prevalence of atrial fibrillation in the Chinese population of mainland China. J Epidemiol 18: 209-216, 2008.

4. Piccini JP, Hammill BG, Sinner MF, et al: Incidence and prevalence of atrial fibrillation and associated mortality among Medicare beneficiaries, 1993-2007. Circ Cardiovasc Qual Outcomes 5: 85-93, 2012.

5. Camm AJ, Lip GY, De Caterina R, et al; ESC Committee for Practice Guidelines (CPG): 2012 focused update of the ESC Guidelines for the management of atrial fibrillation: An update of the 2010 ESC Guidelines for the management of atrial fibrillation. Developed with the special contribution of the European Heart Rhythm Association. Eur Heart J 33: 2719-2747, 2012.

6. Wann LS, Curtis AB, January CT, et al; 2006 Writing Committee Members; ACCF/AHA Task Force Members: 2011 ACCF/AHA/HRS focused update on the management of patients with atrial fibrillation (updating the 2006 guideline): A report of the American College of Cardiology Foundation/American Heart Association Task Force on Practice Guidelines. Circulation 123: 104-123, 2011.

7. Benjamin EJ, Wolf PA, D'Agostino RB, Silbershatz H, Kannel WB and Levy D: Impact of atrial fibrillation on the risk of death: The Framingham Heart Study. Circulation 98: 946-952, 1998.

8. Verma A, Macle L, Cox J and Skanes AC; CCS Atrial Fibrillation Guidelines Committee: Canadian Cardiovascular Society atrial fibrillation guidelines 2010: Catheter ablation for atrial fibrillation/atrial flutter. Can J Cardiol 27: 60-66, 2011.

9. Krittayaphong R, Raungrattanaamporn O, Bhuripanyo $\mathrm{K}$, et al: A randomized clinical trial of the efficacy of radiofrequency catheter ablation and amiodarone in the treatment of symptomatic atrial fibrillation. J Med Assoc Thai 86 (Suppl 1): 8-16, 2003.

10. Wazni OM, Marrouche NF, Martin DO, et al: Radiofrequency ablation vs. antiarrhythmic drugs as first-line treatment of symptomatic atrial fibrillation: A randomized trial. JAMA 293 2634-2640, 2005.

11. Oral H, Pappone C, Chugh A, et al: Circumferential pulmonary-vein ablation for chronic atrial fibrillation. N Engl J Med 354: 934-941, 2006.
12. Stabile G, Bertaglia E, Senatore G, et al: Catheter ablation treatment in patients with drug-refractory atrial fibrillation: A prospective, multi-centre, randomized, controlled study (Catheter Ablation For The Cure Of Atrial Fibrillation Study). Eur Heart J 27: 216-221, 2006.

13. Jais P, Cauchemez B, Macle L, et al: Catheter ablation versus antiarrhythmic drugs for atrial fibrillation: Rhe A4 study. Circulation 118: 2498-2505, 2008.

14. Forleo GB, Mantica M, De Luca L, et al: Catheter ablation of atrial fibrillation in patients with diabetes mellitus type 2: Results from a randomized study comparing pulmonary vein isolation versus antiarrhythmic drug therapy. J Cardiovasc Electrophysiol 20: 22-28, 2009.

15. Wilber DJ, Pappone C, Neuzil P, et al: Comparison of antiarrhythmic drug therapy and radiofrequency catheter ablation in patients with paroxysmal atrial fibrillation: A randomized controlled trial. JAMA 303: 333-340, 2010.

16. Pappone C, Vicedomini G, Augello G, et al: Radiofrequency catheter ablation and antiarrhy thmic drug therapy: A prospective, randomized, 4-year follow-up trial: The APAF study. Circ Arrhythm Electrophysiol 4: 808-814, 2011.

17. Morillo CA, Verma A,Connolly SJ,Kuck KH,Nair GM,Champagne J, Sterns LD, Beresh H, Healey JS and Natale A; RAAFT-2 Investigators: Radiofrequency ablation vs antiarrhythmic drugs as first-line treatment of symptomatic atrial fibrillation (RAAFT 2): A randomized trial. JAMA 311: 692-700, 2014.

18. Cosedis Nielsen J, Johannessen A, Raatikainen P, et al: Radiofrequency ablation as initial therapy in paroxysmal atrial fibrillation. N Engl J Med 367: 1587-1595, 2012.

19. Blandino A, Toso E, Scaglione M, et al: Long-term efficacy and safety of two different rhythm control strategies in elderly patients with symptomatic persistent atrial fibrillation. J Cardiovasc Electrophysiol 24: 731-738, 2013.

20. Higgins JPT and Green S (eds): Cochrane Handbook for Systematic Reviews of Interventions Version 5.1.0 [updated March 2011]. The Cochrane Collaboration, 2011. Available from www.cochrane-handbook.org.

21. Guyatt GH, Oxman AD, Vist GE, et al; GRADE Working Group: GRADE: An emerging consensus on rating quality of evidence and strength of recommendations. BMJ 336: 924-926, 2008.

22. Ionescu-Ittu R, Abrahamowicz M, Jackevicius CA, et al: Comparative effectiveness of rhy thm control vs rate control drug treatment effect on mortality in patients with atrial fibrillation. Arch Intern Med 172: 997-1004, 2012.

23. Tsadok MA, Jackevicius CA, Essebag V, et al: Rhythm versus rate control therapy and subsequent stroke or transient ischemic attack in patients with atrial fibrillation. Circulation 126: 2680-2687, 2012.

24. Pappone C, Rosanio S, Augello G, et al: Mortality, morbidity and quality of life after circumferential pulmonary vein ablation for atrial fibrillation: Outcomes from a controlled nonrandomized long-term study. J Am Coll Cardiol 42: 185-197, 2003.

25. Khaykin Y, Wang X, Natale A, et al: Cost comparison of ablation versus antiarrhythmic drugs as first-line therapy for atrial fibrillation: An economic evaluation of the RAAFT pilot study. J Cardiovasc Electrophysiol 20: 7-12, 2009.

26. McKenna C, Palmer S, Rodgers M, et al: Cost-effectiveness of radiofrequency catheter ablation for the treatment of atrial fibrillation in the United Kingdom. Heart 95: 542-549, 2009.

27. Reynolds MR, Zimetbaum P, Josephson ME, Ellis E, Danilov T and Cohen DJ: Cost-effectiveness of radiofrequency catheter ablation compared with antiarrhythmic drug therapy for paroxysmal atrial fibrillation. Circ Arrhythm Electrophysiol 2: 362-369, 2009.

28. Noro M, Kujime S, Ito N, et al: Cost effectiveness of radiofrequency catheter ablation vs. medical treatment for atrial fibrillation in Japan. Cost performance for atrial fibrillation. Circ J 75: 1860-1866, 2011.

29. Noheria A, Kumar A, Wylie JV Jr and Josephson ME: Catheter ablation vs. antiarrhythmic drug therapy for atrial fibrillation: A systematic review. Arch Intern Med 168: 581-586, 2008.

30. Piccini JP, Lopes RD, Kong MH, Hasselblad V, Jackson K and Al-Khatib SM: Pulmonary vein isolation for the maintenance of sinus rhythm in patients with atrial fibrillation: A meta-analysis of randomized, controlled trials. Circ Arrhythm Electrophysiol 2: 626-633, 2009.

31. Bonanno C,Paccanaro M,La Vecchia L, Ometto R and Fontanelli A: Efficacy and safety of catheter ablation versus antiarrhythmic drugs for atrial fibrillation: A meta-analysis of randomized trials. J Cardiovasc Med (Hagerstown) 11: 408-418, 2010. 